\title{
Synthesis and Characterization of Functionalize HY Zeolite With Sulfunic Acid, A Micro-meso Structure as an Efficient Reusable Catalyst in Organic Transformations
}

Mojgan Zendehdel ( $\square$ m-zendehdel@araku.ac.ir)

Arak University

Fatemeh Tavakoli

Arak University

\section{Research Article}

Keywords: Micro-meso structure, HY zeolite, Functionalized, N-Formylation, Coumarin

Posted Date: April 14th, 2021

DOl: https://doi.org/10.21203/rs.3.rs-392772/v1

License: (c) (1) This work is licensed under a Creative Commons Attribution 4.0 International License. Read Full License 


\section{Abstract}

A new class of catalyst has been prepared with sulfunic acid functionalized $\mathrm{HY}$ zeolite $\left(\mathrm{HY}-\mathrm{N}-\mathrm{SO}_{3} \mathrm{H}\right)$ and characterized by FESEM, TEM, FTIR, TGA, XRD and BET. The result show that the catalyst has the micromeso structure without ordering in the mesophase. Then, two sets of organic reaction were examined to consider of catalytic activity. The micro-meso structure $\mathrm{HY}-\mathrm{N}-\mathrm{SO}_{3} \mathrm{H}$ was used as an acidic catalyst to synthesis of coumarins via Pechmann reaction and facile transformation of amines to formamides under solvent free condition. This catalyst was compared with $\mathrm{NaY}-\mathrm{N}-\mathrm{SO}_{3} \mathrm{H}$ and $\mathrm{MCM}-\mathrm{N}-\mathrm{SO}_{3} \mathrm{H}$ and pure porous material to consider of the effect of acidity and kind and size of porous in the catalyst. The significant advantages of $\mathrm{HY}-\mathrm{N}-\mathrm{SO}_{3} \mathrm{H}$ respect to other catalyst are short reaction times, high yields, pure products, mild conditions and easy workup. In addition, we report an original and environmentally friendly solventfree procedures which reusability of catalyst makes this method nearly green and environmental friendly.

\section{Introduction}

Zeolites are an important class of microporous crystalline aluminosilicates. They are extremely useful as adsorbent, separator, ion exchange and heterogeneous catalyst in relevant industrial processes. Due to the presence of strong acidic sites, large specific surface area, shape selectivity and good thermal stability [1]. However, in most processes and especially catalytic reactions, the size of zeolites leads to the limitations such as low mass transfer problem, and low diffusion for branched molecules and reagent containing mesoporous and macroporous [2].

In recent years, there are many particular attentions to the creation of micro-mesoporous structure of zeolite. Micro-mesoporous zeolite has emerged as important catalytic materials, which has significant number of advantages with respect to both zeolites and mesoporous materials. Literature reviews show that functionalization by some groups have been used for preparation of hierarchical zeolite [3]. The term hierarchical zeolites have been applied for designing zeolites containing a bimodal porosity and showing good acidity and also diffusional restrictions $[4,5]$. Sulfunic acid is nonvolatile, noncorrosive, stable, water resistance and incapable of forming complexes, making it an outstanding alternative to metal catalysts in different areas of organic synthesis as an efficient and green reagent [6]. However, the main drawback of sulfunic acid is separation from reaction mixtures which against the reuse of catalyst. To overcome this problem, sulfunic acid immobilized on some surface such as magnetic [7], Natrolite [8] and Mesoporous materials $[9,10 \mathrm{NEW}]$. Literature review show that the heterogonous catalysts with micromeso structure can be a logical step to increasing the lifetime and reusability of catalyst which and lead to green chemistry for catalytic reaction. In this work, we introduce a mild method to preparation a micromeso structure HY zeolite by functionalized with sulfunic acid for the first time. [10NEW]SADEGH ROSTAMNIARostamnia, S., \& Hassankhani, A. (2014). Covalently bonded ionic liquid-type sulfamic acid onto SBA-15: SBA-15/NHSO3H as a highly active, reusable, and selective green catalyst for solvent-free synthesis of polyhydroquinolines and dihydropyridines. Synlett, 25(19), 2753-2756. 
Interestingly, coumarin and its derivatives are an efficient compound in the field of pharmaceuticals, anticancer, anti-HIV, antioxidant activity, inhibitor [11], vasorelaxants [12], hypnotic agrochemicals [13], anthelmintic [14], optical brightening agents [15], dispersed fluorescent and dye lasers [16]. Synthesis of

coumarins has been carried out by several methods [11] which the most widely used and easy method is pechmann reaction.

Recently, some catalysts such as, CNC@AMPD@Pd [17], poly (4-vinylpyridine) supported copper iodide [18], SBA-15-Ph-PrSO ${ }_{3} \mathrm{H}$ [19], $\mathrm{Fe}_{3} \mathrm{O}_{4} @ \mathrm{SiO}_{2} @ \mathrm{PrSO}_{3} \mathrm{H}$ [20], Au@pSiO 2 [21] PEG-SO ${ }_{3} \mathrm{H}$ [22],

[MTMSPIm]Cl@HY-Z [23] and $\mathrm{Zn}_{0.925} \mathrm{Ti}_{0.075} \mathrm{O}$ [24] have been used for synthesis of coumarin via pechmann reaction.

In addition, formamides was considered as valuable intermediates in the production of various pharmaceuticals. The transformation of primary and secondary amines leads to useful products that are applicable as polar solvents [25]. In the synthesis of complex organic molecules like natural products, protection of functional groups plays a critical role. The N-bonded formyl group is known as temporary and important protection group in peptide synthesis [26].

Various formylating reagents have been used during the last decade such as chloral, activated formic acid using $\mathrm{EDCl}$, ammonium formate, aq. $85 \%$ formic acid and $\mathrm{ZnO}$, carbon monoxide or carbon dioxide, acetic formic anhydride [27], $\mathrm{Na}_{2} \mathrm{SO}_{3}$ [28,29]. However, some of these reported methods for two sets reactions have several difficulties and disadvantages such as costly and toxic reactants, long reaction times, multistep synthesis, high temperature, low yields, production of side products and environmental pollution due to leaching of some elements [30] cause by using non-green solvents, tedious work up, waste control, complex isolation and recovery procedures.

In this paper, we designed hybrid micro-mesoporous $\mathrm{HY}$ zeolite by functionalized with sulfunic acid (HY$\mathrm{N}-\mathrm{SO}_{3} \mathrm{H}$ ) which was used as an efficient and heterogeneous acidic catalyst to preparation of coumarins via pechmann condensations and formylation of amines under solvent free reaction conditions (Scheme1). In addition, the result was comprised with acidic $\mathrm{MCM}-\mathrm{N}-\mathrm{SO}_{3} \mathrm{H}$ with mesoporous structure.

\section{Experimental}

All used chemicals were purchased from Merck and Fluka Companies. The NaY zeolite was purchased from ... company. Melting points were determined on an electro thermal digital melting point apparatus Final product characterized with X-Ray diffract meter (Philips 8440) with radiation at room temperature Cu-Ka, FT-IR (Galaxy series FT-IR 5000 spectrometer), TG-DTA (Rheometric scientific STA-1500 thermo gravimetric analyzer), BET apparatus (ASAP 2020 V3.04 E with adsorption of nitrogen at $76.34^{\circ} \mathrm{K}$ ) was used. NMR spectra were recorded on a Bruker $(300 \mathrm{MHz})$ spectrometer. Chemical shifts (ppm) were referenced to the internal standards Tetramethylsilane (TMS). The Elemental Analyzer (Elemental, Vario EL III) performed microanalyses at the Arak University. The Microanalyses results were agreed favorably 
with the calculated values. Reactions were monitored by thin layer chromatography using silica gel $F_{254}$ aluminum sheets (Merck).

\subsection{Preparation of HY Zeolite}

NaY Zeolite $(1 \mathrm{~g})$ added to $200 \mathrm{ml}$ of $\mathrm{NH}_{4} \mathrm{Cl}$ solution $(0.002 \mathrm{M})$ and stirred for 24 hours. Then the solid filtered and washed with water and the powder was calcinated in $300^{\circ} \mathrm{C}$ for $5 \mathrm{~h}$ to remove $\mathrm{NH}_{3}$. $(\mathrm{Si} / \mathrm{Al}=$ 2.9)

\subsection{Preparation of $\mathrm{MCM}-41$}

MCM-41 was synthesized by hydrolysis of structure-directing agent CTAB (cetyltrimethyl ammonium bromide) and TEOS, as a silica source in acidic solution, with a reactant molar composition of 1.0 CTAB:7.5 TEOS:1.8 HCl:500 $\mathrm{H}_{2} \mathrm{O}$. The gel mixture was then hydrothermally held at $100^{\circ} \mathrm{C}$ for $24 \mathrm{~h}$ in an autoclave. After that the solid product filtration, washed with deionized water, and air dried. The collected product was calcined at $550^{\circ} \mathrm{C}$ for $6 \mathrm{~h}$.

\subsection{General procedure for synthesis of $\mathrm{HY}-\mathrm{N}-\mathrm{SO}_{3} \mathrm{H}$ and $\mathrm{MCM}-\mathrm{N}-\mathrm{SO}_{3} \mathrm{H}$}

$1 \mathrm{~g}$ of porous materials (HY zeolite or MCM-41) was added to a mixture of dry toluene $(20 \mathrm{~mL})$ and trimethoxysilyl propylamine $(2 \mathrm{~mL})$ and for 24 hours in reflux condition at $120^{\circ} \mathrm{C}$. Then, catalyst was filtered and dried at $60^{\circ} \mathrm{C}$. Then, Chlorosulfonic acid $(1 \mathrm{~mL})$ and triethylamine $(0.05 \mathrm{~mL})$ was added to a mixture of Amine functionalized zeolite $(1 \mathrm{~g})$ in dry toluene $(20 \mathrm{~mL})$ and refluxed at $120^{\circ} \mathrm{C}$ for 24 hours. Then, sulfonated zeolite was filtrated and dried. $(\mathrm{Si} / \mathrm{Al}=3.4)$ The catalyst was characterized by FT-IR, XRD, TGA, FESEM, TEM, EDX, BET, and CHN analysis.

\subsection{General procedure for pechmann reaction}

A mixture of phenol or Resorcinol $(1 \mathrm{mmol})$ and ethyl acetoacetate $(1 \mathrm{mmol})$ was added to a flask which immersed in an oil bath, $(0.04 \mathrm{~g})$ of synthesized catalysts $\left(\mathrm{HY}-\mathrm{N}-\mathrm{SO}_{3} \mathrm{H}\right.$ and $\left.\mathrm{MCM}-\mathrm{N}-\mathrm{SO}_{3} \mathrm{H}\right)$ and heated at $130^{\circ} \mathrm{C}$ under solvent free conditions. The progress of the reaction was monitored by thin-layer chromatography (TLC). After completion of the reaction, the catalyst was separated by simple filtration. The obtained product was recrystallized from hot ethanol, dried and characterized by FT-IR, ${ }^{1} \mathrm{H}$ NMR and ${ }^{13} \mathrm{C}$ NMR spectroscopy.

\subsection{General procedure for formylation of amines}

To mixture of aniline $(1 \mathrm{mmol})$ and catalyst $(0.02 \mathrm{~g})$ was added formic acid $(1.2 \mathrm{mmol})$ and stirred at room temperature for appropriate time. The progress of reaction followed by TLC. After compilation reaction, products extracted by ethanol and chloroform $(4 \mathrm{~mL})$ and catalyst was filtrated, washed and dried for reuse. The effect of solvent was considered in the presence of $1 \mathrm{~mL}$ of different solvents (Table 
2, entry 6,7 and 8). The structures of the products were established from their physical properties and spectral ( ${ }^{1} \mathrm{H}$ NMR, ${ }^{13} \mathrm{C}$ NMR and FT-IR) analysis and compared with the data reported in the literatures.

\section{Result And Discussion}

The heterogeneous sulfunic acid that grafted outside of amino functionalized porous material ( $\mathrm{HY}$ and MCM-41) have been characterized as follows:

\subsection{FT-IR Analysis}

FT-IR spectra of pure $\mathrm{HY}$ zeolite, $\mathrm{HY}-\mathrm{NH}_{2}, \mathrm{HY}-\mathrm{N}-\mathrm{SO}_{3} \mathrm{H}$ and $\mathrm{MCM}-\mathrm{N}-\mathrm{SO}_{3} \mathrm{H}$ are presented in Fig.1.a-d. The FTIR spectra of all samples indicate an intense band about ca. $1022 \mathrm{~cm}^{-1}$ attributable to the asymmetric stretching of $\mathrm{T}-\mathrm{O}-\mathrm{T}(\mathrm{T}=\mathrm{Si}, \mathrm{Al})$ chain of porous materials. The symmetric stretching and bending frequency bands of T-O-T framework of porous materials appear at ca.791 and $463 \mathrm{~cm}^{-1}$, respectively [31]. Fig.1a,c shows FT-IR spectrum of HY zeolite and MCM-41 and Fig.1.b,d shows spectrum of HY-N$\mathrm{SO}_{3} \mathrm{H}, \mathrm{MCM}-\mathrm{N}-\mathrm{SO}_{3} \mathrm{H}$, the characteristic absorption correlated to $\mathrm{S}=0$ stretching appeared at $1255 \mathrm{~cm}^{-1}$, the stretching band and out of plane bending related to O-H group appeared at 3400-3500 and $797 \mathrm{~cm}^{-1}$, respectively which confirm the presence of $-\mathrm{SO}_{3} \mathrm{H}$ groups function on the porous materials [32].

\subsection{XRD Analysis}

The immobilized catalysts were also characterized by powder X-ray diffraction. The patterns for HY, HY$\mathrm{NH}_{2}$ and $\mathrm{HY}-\mathrm{N}-\mathrm{SO}_{3} \mathrm{H}$ are shown in Fig.2.a-c. While the XRD analysis is not quantitative, the diffraction patterns after the binding of 3-APTES and also after the grafting of sulfunic acid are similar to that of the pure zeolite support. According to similar studies, in the present study no changes were detected in the crystalline structure of zeolite during the immobilization procedures, also the percentage of amorphous phase is small [33]. Fig.3.a show the XRD pattern in the low angle ranges $\mathrm{HY}-\mathrm{N}-\mathrm{SO}_{3} \mathrm{H}$, which there are not any reflectance, which confirmed the mesoporous phase, is not ordered in the $\mathrm{HY}-\mathrm{N}-\mathrm{SO}_{3} \mathrm{H}$. In the case of MCM-41, Fig.3.b three (100), (110) and (200) lines related to hexagonal pore symmetry of MCM-41 can be observed which after functionalize with sulfunic acid the intensity of them decreased due to distortion that occurs on the channels of the mesoporous materials [34].

\subsection{TG-DTA Analysis}

To illustrate the thermal stability of $\mathrm{HY}-\mathrm{N}-\mathrm{SO}_{3} \mathrm{H}$ materials, TG-DTA analysis of these samples has been carried out under $\mathrm{N}_{2}$ flow. TG- DTA plots and DTG pattern for these materials are shown in Fig.4 TG curve of $\mathrm{HY}-\mathrm{N}-\mathrm{SO}_{3} \mathrm{H}$ revealed an initial weight loss of $7.509 \%$ up to $200{ }^{\circ} \mathrm{C}$ due to the decomposition of physical and chemical adsorbed water in it. The second steps, show the complete loss weight of the organic species and hydroxyl groups (20.94\%), which observed in the temperature range of $250-450{ }^{\circ} \mathrm{C}$. In the last step, the structure of zeolite is changed. On TGA curve of HY zeolite, there are two obvious peaks: a peak around $120^{\circ} \mathrm{C}$ caused by the loss of zeolite-adsorbed water and a peak at $1100{ }^{\circ} \mathrm{C}$, 
probably caused by self-dehydroxylation of $-\mathrm{OH}$ group on the surface of the zeolite[ref* $35 \mathrm{new}]$. Moreover, the investigation of the DTA pattern show some small endothermic peak around $250-450{ }^{\circ} \mathrm{C}$ attributed to the dehydration of the hydroxyl groups inside the micro and meso phases $[36,23]$ and a broad endothermic peaks related to amine and sulfunic acid decomposition. These results confirmed the immobilization of organic materials on the zeolite.

[ref* 35 new] Li, Z., Xie, K., \& Slade, R. C. (2001). Studies of the interaction between CuCl and HY zeolite for preparing heterogeneous Cul catalyst. Applied Catalysis A: General, 209(1-2), 107-115.

\subsection{FESEM, EDS, TEM, BET and Elemental Analysis}

In Fig.5.a,b we have seen the FESEM micrographs of heterogenized $\mathrm{HY}$ and sulfunic acid $\left(\mathrm{HY}-\mathrm{N}-\mathrm{SO}_{3} \mathrm{H}\right)$ sample with a wide range of shapes and sizes of particles. The presence of well-defined zeolite crystals with some shadow indicated presence of organic group on the external surface. The particle sizes for HY are around $500 \mathrm{~nm}$. The particle sizes for $\mathrm{HY}-\mathrm{N}-\mathrm{SO}_{3} \mathrm{H}$ are about $150-200 \mathrm{~nm}$ that the decrease of size for modified zeolite is due to the complex formation on the support [37]. Also, in Fig.5.c the shows TEM some worm like changing in the surface of zeolite which may be due to disorder meso structure in the surface of $\mathrm{HY}-\mathrm{N}-\mathrm{SO}_{3} \mathrm{H}$ zeolite [38].

The presence of $\mathrm{C}, \mathrm{O}, \mathrm{Al}, \mathrm{Si}, \mathrm{S}$ and $\mathrm{N}$ atoms was observed in the EDX spectrum Fig.5.d. It is observed that the peaks corresponding to $\mathrm{Si}, \mathrm{Al}$ and $\mathrm{O}$ were contributed by aluminosilicates present in the sample. Remarkably, the results Elemental Analysis show the ratio 4 for Si/Al, which confirms the present of $\mathrm{HY}$ zeolite without any changes in its structure and the result of $\mathrm{CHN}$ confirm the $\mathrm{C} / \mathrm{N}$ ratio about 3 for $\mathrm{HY}-\mathrm{N}$ $\mathrm{SO}_{3} \mathrm{H}$.

Nitrogen absorption-desorption and BJH plots show in the Fig.6.a,b. Noteworthy, in the case of pure HY zeolite which based on IUPAC data Nitrogen absorption-desorption show the I type curve which confirmed the microporous structure. $\mathrm{HY}-\mathrm{N}-\mathrm{SO}_{3} \mathrm{H}$ with the specific surface areas and pore volume of the catalysts that were estimated by nitrogen adsorption at relative pressures $\left(P / P_{0}\right)$ in the range of $0.008-0.35$ (microporous) and 0.35-0.9 with a hysteresis related to mesoporous show in Table 1 and Fig.6.b confirmed the preset micro-meso structure for catalyst [39].

In comparison of $\mathrm{HY}$ zeolite with $\mathrm{HY}-\mathrm{N}-\mathrm{SO}_{3} \mathrm{H}$ materials exhibited decrease in specific surface area and nano porous volumes after functionalization amine and sulfunic acid (Table 1). Since the zeolite framework, structure is not affected by functionalization as shown by the XRD pattern, the reduction of surface area and pore volume provides direct evidence for the presence of organic materials in the surface and cavities [40].

\section{5. $\mathrm{pH}$-analysis}

pH-analysis of $\mathrm{HY}-\mathrm{N}-\mathrm{SO}_{3} \mathrm{H}$ to an aqueous solution of $\mathrm{NaCl}(1 \mathrm{M}, 25 \mathrm{ml})$ with initial $\mathrm{pH} 5.93,500 \mathrm{mg}$ of $\mathrm{HY}$ $\mathrm{N}-\mathrm{SO}_{3} \mathrm{H}$ was added and mixture stirred for $3 \mathrm{~h}$ after which the $\mathrm{pH}$ of solution decreased to 1.74 . This is 
equal to a loading of $0.9 \mathrm{mmol} \mathrm{SO}_{3} \mathrm{H}$ obtained back-titration analysis of the catalyst.

\section{Catalytic studies}

\subsection{Preparation of coumarins via pechmann condensations}

Here, we examined the catalytic activity of $\mathrm{HY}-\mathrm{N}-\mathrm{SO}_{3} \mathrm{H}$ and comprised with $\mathrm{NaY}-\mathrm{N}-\mathrm{SO}_{3} \mathrm{H}$ and $\mathrm{MCM}-\mathrm{N}-$ $\mathrm{SO}_{3} \mathrm{H}$ as catalyst for the synthesis of coumarin compounds under pechmann condensation. At first, we selected Resorcinol as the primery substance of reaction mixed with ethyl acetoacetate in presence different amounts of synthesized catalyst $(0.02-0.1 \mathrm{~g})$ at $110{ }^{\circ} \mathrm{C}$ to investigated the effect of catalyst amount on percentage conversion (Table 2, entry 1-4). The result show that the $0.08 \mathrm{~g}$ of catalyst is the best amount of catalyst (entry 3 ) which use to prepared of coumarin. The results in Table 2 show that the yield of reaction is trace without using of catalyst for two derivative (entry 17). To consider the effect of solvents on the preparation of coumarin with functionalized HY zeolite with sulfunic acid, in the optimum conditions some usual solvents were used (entries 6-9). The result show that with use of these solvents comparing to the solvent free condition the yield of reaction decreased. It seems the interaction between these polar solvents and oxygen groups in the catalyst sites to inhibit the formation coumarin. The creating solvent free conditions for organic reaction are the advantageous in this work, which avoids the use of environmental hazardous and toxic solvents that are importance problems for green chemistry. Literature review show that there are not definite mechanism but based on other works a suggested mechanism shows in Scheme 2 to the formation of coumarin. In the first, acidic catalyst activated the hydroxyl of phenolic groups and protonated ethyl acetoacetate and phenolic groups and then resorcinol making nucleophilic attack to the carbonyl group. In the next steps, between reactants, transesterification was occurred and proton absorbed to catalyst again. Finally, EtOH and $\mathrm{H}_{2} \mathrm{O}$ removing and coumarin derivatives were synthesized.

\subsection{Formylation of amines}

At first, aniline has been selected as the model reaction and all reaction conditions have been studied and optimized which results summarized in Table 3. The result show that without using of catalyst, no creating any product (Table 3, entry 9 ). Therefore, it seems that the acidity of the catalyst is effective for this reaction. As obtained, best yields and reaction times was obtained using $10 \mathrm{~mol} \%(0.02 \mathrm{~g})$ of catalyst in the $9 \mathrm{~min}$ at solvent free condition (entry 3). Literature reviews show that solvent plays an important role in catalytic behavior because it can make different phases uniform, thus promoting mass transportation which could also change the reaction mechanism by affecting the intermediate species, the surface properties of catalysts and reaction pathways [39 41]. The effect of solvents were considered in the (entries 6, 7 and 8), results show that the time of reaction was reduced. As we known, one of the most importance problems for green chemistry are the creating solvent free conditions for organic reaction, which avoids the use of environmental hazardous and toxic solvents. Then, we have continued our work in solvent free condition. 
We can see the proposed mechanism in Scheme 3 which based on this proposed mechanism acidity of the catalyst is effective for this reaction because help to protonated hydroxyl group and creating a positive carbon which suitable to attack of amine group and lead to formylation reactions.

Therefore, in this optimized condition, several aniline derivatives have been $\mathrm{N}$-formylated to corresponding formamides in good yields and short reaction times (Table 4). In comparison of different substituents reveals that electron releasing groups such as Methyl (entry 2) accelerate the reaction and lead to shorter reaction times, on the other hands, electron with drawing groups such as $\mathrm{Cl}$ and $\mathrm{NO}_{2}$ (entries 3-7) whereas lower the rates and lead to longer reaction times. In addition, orthophenylendiamine has been formylated in both amine groups (entry 8).

To consider the effect of acidity and type of porous size in the catalyst, we compared the catalytic activity of $\mathrm{HY}-\mathrm{N}-\mathrm{SO}_{3} \mathrm{H}$ with pure $\mathrm{NaY}, \mathrm{HY}, \mathrm{MCM}-41, \mathrm{NaY}-\mathrm{N}-\mathrm{SO}_{3} \mathrm{H}$ and MCM-N-SO${ }_{3} \mathrm{H}$ (Table 2 entries 10-16 and Table 3 entries 10-14). The result show that the acidity of zeolite can be effective on the two set reaction (Table 2 and 3 entries 10,11) but the increasing the size of porous alone doesn't any significant effect on the formylation of amine and synthesis of coumarine (Table 2 and 3 entries 12). In the other hand with functionalize sulfunic acid on the MCM-41 the acid site increasing which caused the increasing of yield (Table 2 entries 15,16 and Table 3 entry 14). Finally, in the case of $\mathrm{HY}-\mathrm{N}-\mathrm{SO}_{3} \mathrm{H}$, the both acidity of zeolite and sulfunic acid can be useful for organic reactions. It seems functionalized of HY zeolite by sulfunic acid with a micro-meso structure have bigger porous size and higher stability respect to HY and MCM-41 which suitable for entering bulk molecule and increased the yield and lifetime and reusibilty of the catalyst [40 42 44]. 42,43 in table

\section{Recyclability and comprising with other works}

To investigate the catalytic efficiency of the recycled catalyst, successive cycles of the model reaction were run under the optimal reaction conditions using recycled $\mathrm{HY}-\mathrm{N}-\mathrm{SO}_{3} \mathrm{H}$ from the previous run for synthesis of coumarines and formamides (Fig.7). A few change in the yield after each cycle can be due to micro-mesopore structure catalyst that let to catalyst release of products. In Fig.8, we investigated the FTIR and XRD of catalyst after final run was comprised with first run the catalyst was easily recovered by simple filtration, adequately washed with ethanol, dried and was recycled in the model reaction for two set catalysts. The result show that there isn't any change in catalyst and could be reused without any significant loss of activity up to six cycles for $\mathrm{N}$-formylation and pechmann condensation.

The catalytic activity of $\mathrm{HY}-\mathrm{N}-\mathrm{SO}_{3} \mathrm{H}$ with micro-meso structure comparised with other reported heterogeneous catalysts for combination of resorcinol and ethyl acetoacetate to preparing coumarin shows in Table 5.

It is clearly showed from these comparison table that this catalyst display a higher activity and loading under the same reaction condition. Remarkably, the slight amount of catalyst, excellent yield, short reaction time, mild, ecofriendly and solvent free condition lead to excell other works. 
In final, this protocol for formylation of aniline has been compared with some other reported methods in the Table 6. Although these methods are useful or efficient but most of them need to elevated temperature, toxic reagents, long reaction time and large amount of catalyst. Finally they also obtain pour efficiency and side hazardous products. As this table, this methodology improved yields, reaction times or reaction conditions. It seems that both sulfate groups as an acidic agent and HY zeolite catalyze this reaction together and intensify each other's effects.

Then, the sulfunic acid immobilize on the HY zeolite create low cost heterogeneous active catalyst under mild condition for organic reactions and indicating cooperative effect of zeolite support. It seems ,micromeso structure of synthesized catalyst was provide or was obtained bigger acidic porous size and acidity for entering organic molecule which increased the yield and lifetime of the catalyst.

\section{Conclusion}

In conclusion, as a part of our growing interest in the synthesis of comarines and formamides, we have carried out a new, mild, novel, clean and fast methodology for synthesis them, in the presence of micromeso structure $\mathrm{HY}-\mathrm{N}-\mathrm{SO}_{3} \mathrm{H}$ zeolite. This kind of catalyst reduced the reactant molecules diffusion inside the crystal, which cause the increasing availability of active sites that reduce diffusion path of the reactant and coke precursor molecules and mesoporous materials with higher hydrothermal stability and acidity. This catalyst is an environmentally friendly catalyst at room temperature and easy work-up in which the separation techniques are not necessary to get the pure compounds.

\section{Declarations}

\section{Acknowledgments:}

The authors thank Arak University for the scientific and instrumental support and zeolite and porous materials committee of Iranian Chemical Society for supporting of this work. This research did not receive any specific grant from funding agencies in the public, commercial, or not for profit sectors.

\section{References}

1. C.S. Cundy, P.A. Cox, Chem. Rev. (2003) https://doi.org/10.1021/cr020060i

2. M.E. Davis, Nature. (2002) https://doi.org/10.1038/nature00785

3. D.P. Serrano, P. Pizarro, Chem. Soc. Rev. (2013) https://doi.org/10.1039/C2CS35330J

4. O. Fardmousavi, H. Faghihian, C. R. Chim. (2014) https://doi.org/10.1016/j.crci.2014.05.001

5. T.H. Nguyen, S. Kim, M. Yoon, T.H. Bae, ChemSusChem. (2016) https://doi.org/10.1002/cssc.201600004

6. D. Kh. Niknam, Saberi, Tetrahedron Lett. (2009) https://doi.org/10.1016/j.tetlet.2009.06.140 
7. A. Rostamia, B. Tahmasbia, F. Abedib, Z. Shokri, J. Mol. Catal. A: Chem. (2013) https://doi.org/10.1016/j.molcata.2013.06.004

8. M. Nasrollahzadeh, A. Ehsani, A. Rostami-Vartouni, Ultrason. Sonochem. (2014) https://doi.org/10.1016/j.ultsonch.2013.07.012

9. M. Sasidharan, A. Bhaumik, ACS Appl. Mater. Interfaces. (2013) https://doi.org/10.1021/am4000326

10. S. Rostamnia, A. Hassankhani, Synlett. (2014) https://doi.org/10.1055/s-0034-1379477

11. A. Detsi, C. Kontogiorgis, D. Hadjipavlou-Litina, Expert opinion on therapeutic patents. (2017) https://doi.org/10.1080/13543776.2017.1360284

12. E. Quezada, G. Delogu, C. Picciau, L. Santana, G. Podda, F. Borges, Molecules. (2010) https://doi.org/10.3390/molecules 15010270

13. J.F. Cheng, A. Ishikawa, Y. Ono, T. Arrhenius, A. Nadzan, Bioorg. Med. Chem. Lett. (2003) https://doi.org/10.1016/j.bmcl.2003.08.025

14. R.D.H. Murray, J. Mendez, S.A. Brown, John Wiley \& Sons Ltd. (1983) https://doi.org/10.1002/nadc.19830310109

15. M.K. Potdar, S.S. Mohile, M.M. Salunkhe, Tetrahedron Lett.(2001) https://doi.org/10.1016/S00404039(01)02041-X

16. R. Hosseinzadeh, E. Domehri, M. Tajbakhsh, A. Bekhradnia, J. Incl. Phenom. Macro. Chem. (2019) https://doi.org/10.1007/s10847-018-0872-3

17. A. Mirosanloo, D. Zareyee, M.A. Khalilzadeh, Appl. Organomet. Chem. (2018) https://doi.org/10.1002/aoc.4546

18. J. Albadi, F. Shirini, J. Abasi, N. Armand, T. Motaharizadeh, C. R. Chim. (2013) https://doi.org/10.1016/j.crci.2012.10.002

19. B. Karimi, D. Zareyee, Org. Lett. 10 (2008) https://doi.org/10.1021/ol8013107

20. F.K. Esfahani, F. Kabiri, D. Zareyee, R. Yousefi, ChemCatChem. (2014) https://doi.org/10.1002/cctc.201402547

21. M. Yaghoobi, D. Zareyee, M.A. Khalilzadeh, Appl. Organomet. Chem. (2020) https://doi.org/10.1002/aoc.5787

22. G.M. Nazeruddin, M.S. Pandharpatte, K.B. Mulani, C.R. Chim. (2012) https://doi.org/10.1016/j.crci.2011.10.005

23. M. Zendehdel, S. Khaghaninejad, F. Tavakoli, Sh Ganji, J. Iran. Chem. Soc. (2020) https://doi.org/10.1007/s13738-020-01950-x

24. N.H. Jadhav, S.S. Sakate, N.K. Rasal, D.R. Shinde, R.A. Pawar, ACS omega. (2019) https://doi.org/10.1021/acsomega.9b00257

25. J. Deutsch, R. Eckelt, A. Köckritz, A. Martin, Tetrahedron. (2009) https://doi.org/10.1016/j.tet.2009.10.047

26. P.G.M. Wuts, Greene s Protective Groups in Organic Synthesis, E-Publishing (Wiley, Hoboken, NJ, 20140, p. 991 
27. C.J. Gerack, L. McElwee-White, Molecules. (2014) https://doi.org/10.3390/molecules 19067689

28. D. Dan, F. Chen, W. Zhao, H. Yu, S. Han, Y. Wei, Dalton Trans. (2021) https://doi.org/ 10.1039/D0DT03300F

29. Z. Wu, Y. Zhai, W. Zhao, Z. Wei, H. Yu, S. Han, Y. Wei, Green Chem. (2020) https://doi.org/10.1039/C9GC03564H

30. S. Kazemi, A. Mobinikhaledi, M. Zendehdel, Chin. Chem. Lett. (2017) https://doi.org/10.1016/j.cclet.2017.04.029

31. D. Chandra, T. Yokoi, T. Tatsumi, A. Bhaumik, Chem. Mater. (2007) https://doi.org/10.1021/cm701918t

32. L. Ma'mani, M. Sheykhan, A. Heydari, M. Faraji, Y. Yamini, Appl. Catal. A. (2010) https://doi.org/10.1016/j.apcata.2010.01.020

33. X.N. Zhao, H.Ch. Hu, F.J. Zhang, Z.H. Zhang, Appl. Catal. A. (2014) https://doi.org/ 10.1016/j.apcata.2014.06.006

34. D.P. Serrano, J.M. Escola, P. Pizarro, Chem. Soc. Rev. (2013) https://doi.org/10.1039/C2CS35330J

35. Z. Li, K. Xie, R.C. Slade, A. Applied Catalysis, General. (2001) https://doi.org/10.1016/S0926$860 \times(00) 00745-6$

36. E. Amigues, C. Hardacre, G. Keane, M. Migaud, M.O. Neill, Chem. Commun. (2005) https://doi.org/10.1039/b509248e

37. K. Li, J. Valla, J. Garcia-Martinez, Chem. Cat. Chem. (2014) https://doi.org/10.1002/cctc.201300345

38. C.T. Hsieh, W.S. Fan, W.Y. Chen, J.Y. Lin, Sep. Purif. Technol. (2009) https://doi.org/10.1016/j.seppur.2009.03.041

39. D.M. Fernandes, R. Silva, A.A.W. Hechenleitner, E. Radovanovic, M.A.C. Melo, E.A.G. Pineda, Mater. Chem. Phys. (2009) https://doi.org/10.1016/j.matchemphys.2008.11.038

40. K.J. Balkus, A.G. Gabrielov, J. Inclu. Phenom, Mol. Recognition Chem. (1995) https://doi.org/10.1007/978-94-011-0119-6_6

41. M. Salavati-Niasari, A. Sobhani, J. Mol. Catal. A: Chem. (2008) https://doi.org/10.1016/j.molcata.2008.01.030

42. D. Habibi, M. Nasrollahzadeh, H. Sahebekhtiari, J. Mol. Catal. A: Chem. (2013) https://doi.org/10.1016/j.molcata.2013.04.001

43. M. Hong, G. Xiao, J. Fluor. Chem. (2013) https://doi.org/10.1016/j.jfluchem.2012.12.010

44. S. Doherty, P. Goodrich, C. Hardacre, V. Parvulescu, C. Paun, Adv. Synth. Catal. (2008) https://doi.org/10.1002/adsc.200700425

45. J. Martínez, L. Sánchez, F.J. Pérez, V. Carranza, F. Delgado, L. Reyes, R. Miranda, Journal of Chemistry. (2016) https://doi.org/10.1155/2016/4678107

46. A. Sinhamahapatra, N. Sutradhar, S. Pahari, H.C. Bajaj, A.B. Panda, Appl. Catal. A. (2011) https://doi.org/10.1016/j.apcata.2010.12.027 
47. N. Radwan, M. Hagar, T. Afifi, F. Al-wadaani, R. Okasha, Catalysts. (2018) https://doi.org/10.3390/catal8010036

48. A. Mirosanloo, D. Zareyee, M.A. Khalilzadeh, Appl. Organomet. Chem. (2018) https://doi.org/10.1002/aoc.4546

49. F. Rajabi, A. Feiz, R. Luque, Catalysis Letters. (2015) https://doi.org/10.1007/s10562-015-1544-1

50. D. Zareyee, M. Serehneh, J. Mol. Catal. A: Chem. (2014) https://doi.org/10.1016/j.molcata.2014.04.013

51. R. Sun, Y. Gao, Y. Ma, G. Yang, Y. Li, J. Iran. Chem. Soc. (2017) https://doi.org/10.1007/s13738-0161025-5

52. S.A. Khan, S.B. Khan, A.M. Asiri, I. Ahmad, Nanoscale Res. Lett. (2016) https://doi.org/10.1186/s11671-016-1525-3

53. S. Das, A. Majee, A. Hajra, Green Chem. Lett. Rev. (2011) http://doi.org/10.15226/sojmse.2016.00121

54. J. Deng, L.P. Mo, F.Y. Zhao, L.L. Hou, L. Yang, Z.H. Zhang, Green Chem. (2011) http://doi.org/10.1039/c1gc15470b

55. M. Amirsoleimani, M.A. Khalilzadeh, D. Zareyee, J. Mol. Struct. (2012) https://doi.org/10.1016/j.molstruc.2020.129076

56. Y. Shen, Q. Zheng, Z.N. Chen, D. Wen, J.H. Clark, X. Xu, T. Tu, T, Angew. Chem. Int. Ed. (2020) https://doi.org/10.1002/anie.202011260

57. M.I. Ansari, M.K. Hussain, N. Yadav, P.K. Gupta, K. Hajela, Tetrahedron Lett. (2012) https://doi.org/10.1016/j.tetlet.2012.02.027

58. M. Nasrollahzadeh, S.M. Sajadi, A. Hatamifard, J. Colloid Interface Sci. (2015) https://doi.org/10.1016/j.jcis.2015.08.040

59. S. Majumdar, J. De, J. Hossain, A. Basak, Tetrahedron Lett. (2013) https://doi.org/10.1016/j.tetlet.2012.11.017

60. B. Krishnakumar, M. Swaminathan, J. Mol. Catal. A: Chem. (2011) https://doi.org/10.1016/j.molcata.2010.11.002

61. J.-G. Kim, D.O. Jang, Synlett. (2010) https://doi.org/10.1055/s-0030-1258518

\section{Tables}

Due to technical limitations, table 1 to 6 is only available as a download in the Supplemental Files section.

\section{Figures}




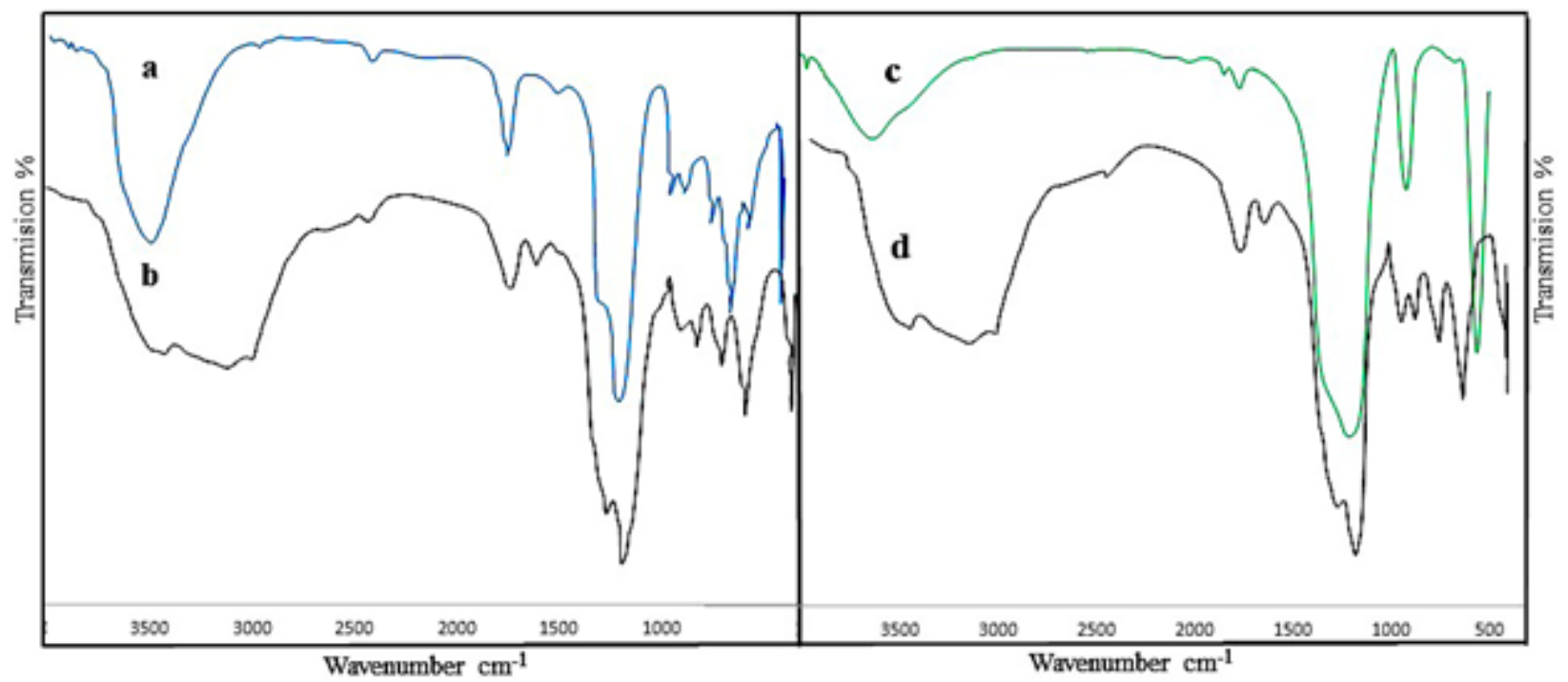

Figure 1

FT-IR spectra of a) HY zeolite, b) HY-N-SO3H, c) MCM-41, d) MCM-N-SO3H

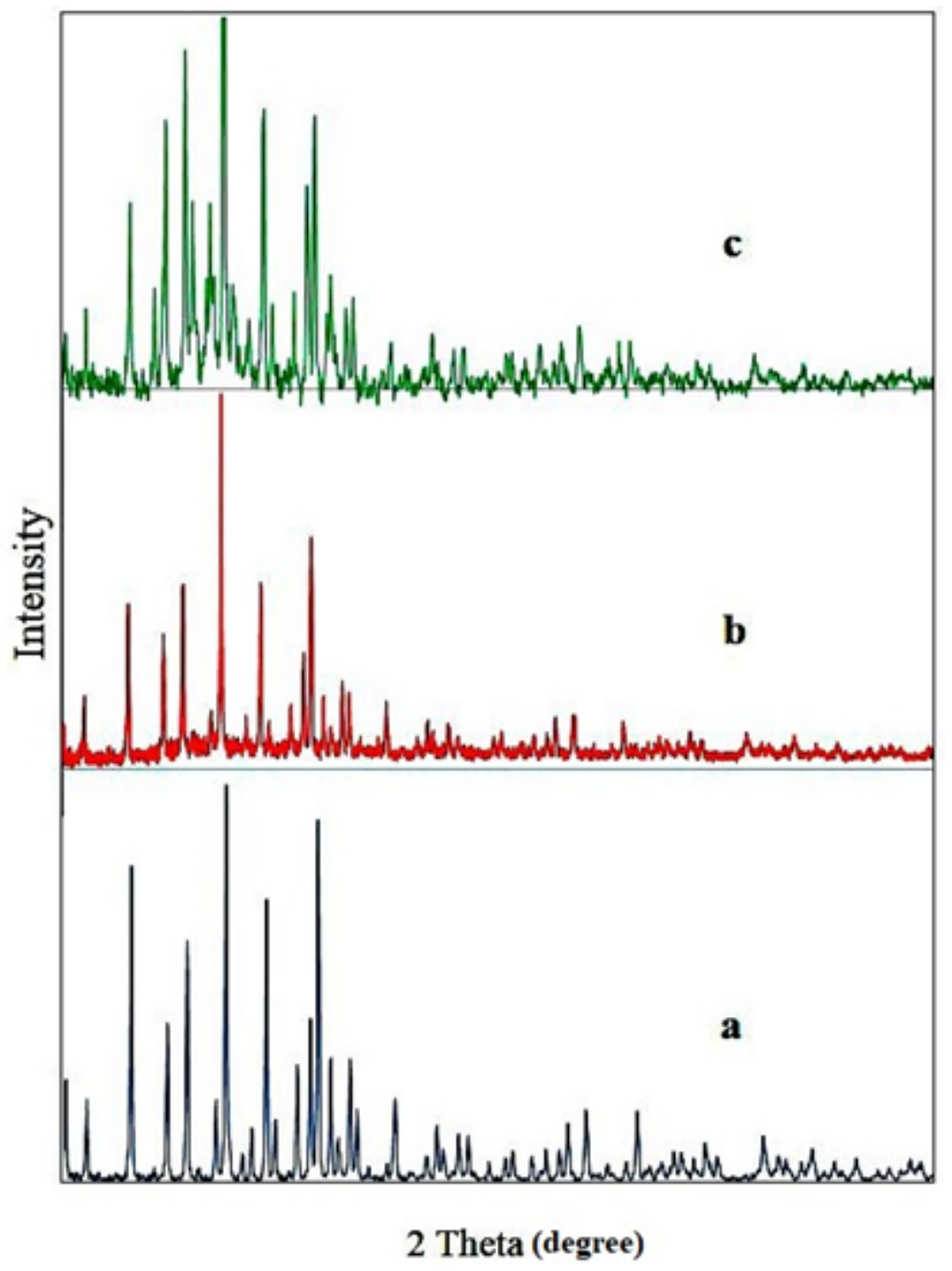

Figure 2 
XRD of prepared materials: a) HY zeolite, b) HY-NH2, c) HY-N-SO3H

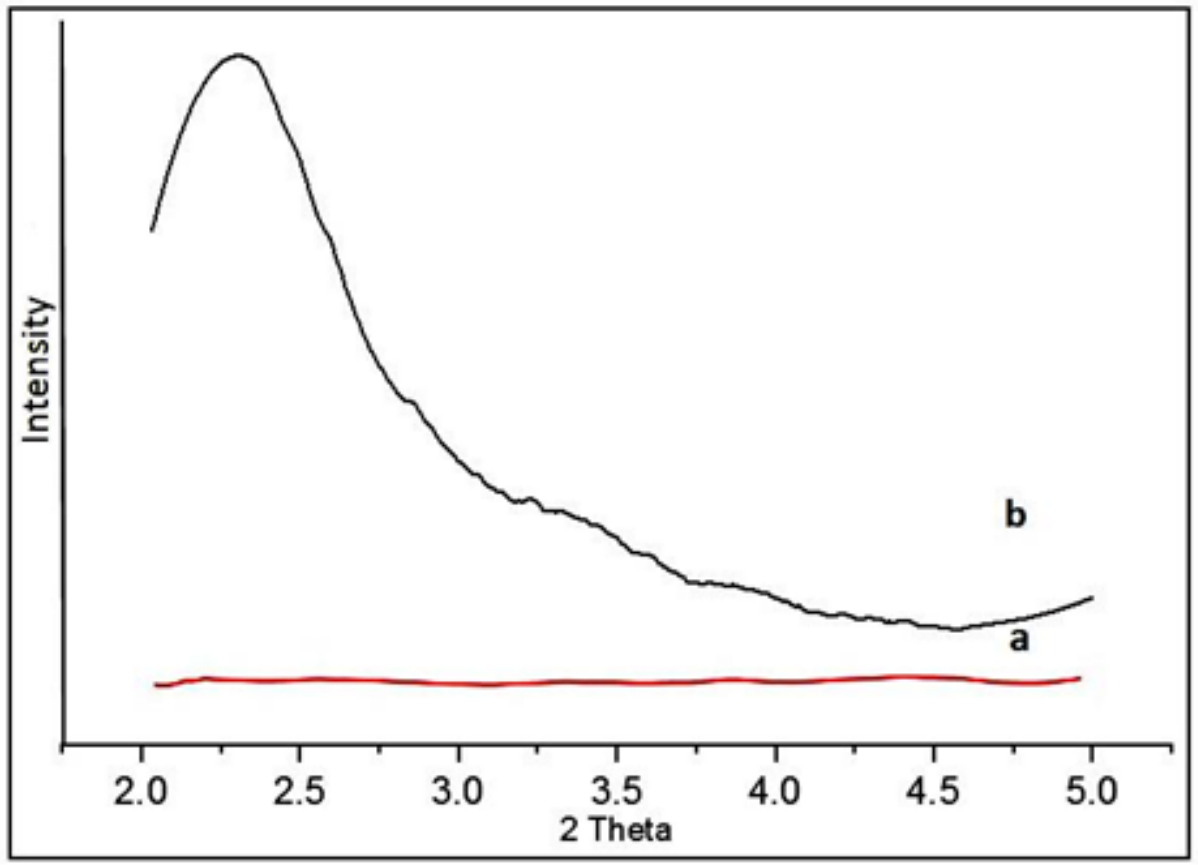

Figure 3

Low-angle XRD of prepared materials: a) HY-N-SO3H b) MCM-N-SO3H

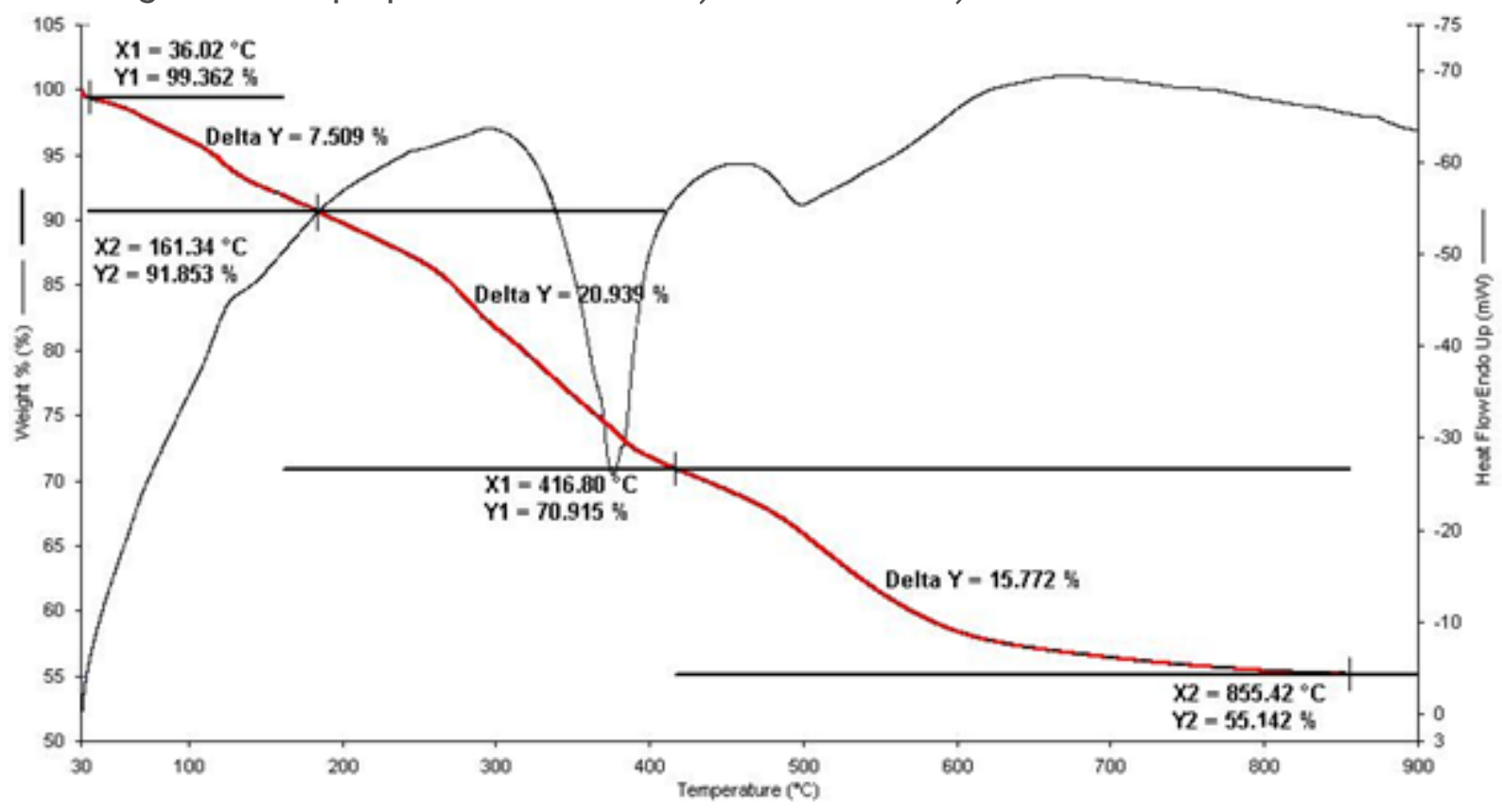

Figure 4

TGA/DTA of prepared HY-N-SO3H 


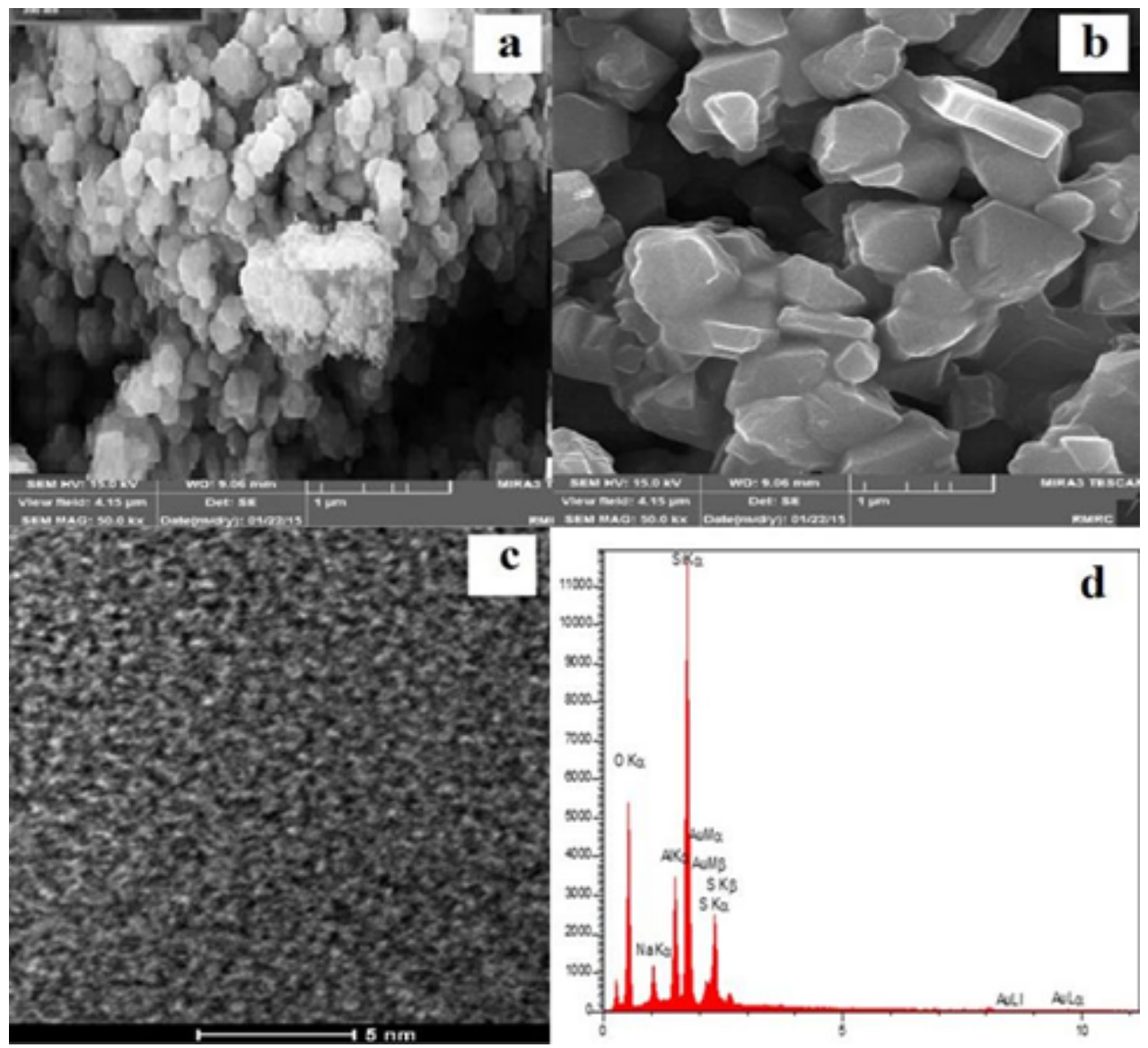

Figure 5

FESEM of a) HY zeolite b) HY-N-SO3H c) TEM of HY-N-SO3H d) EDS of HY-N-SO3H
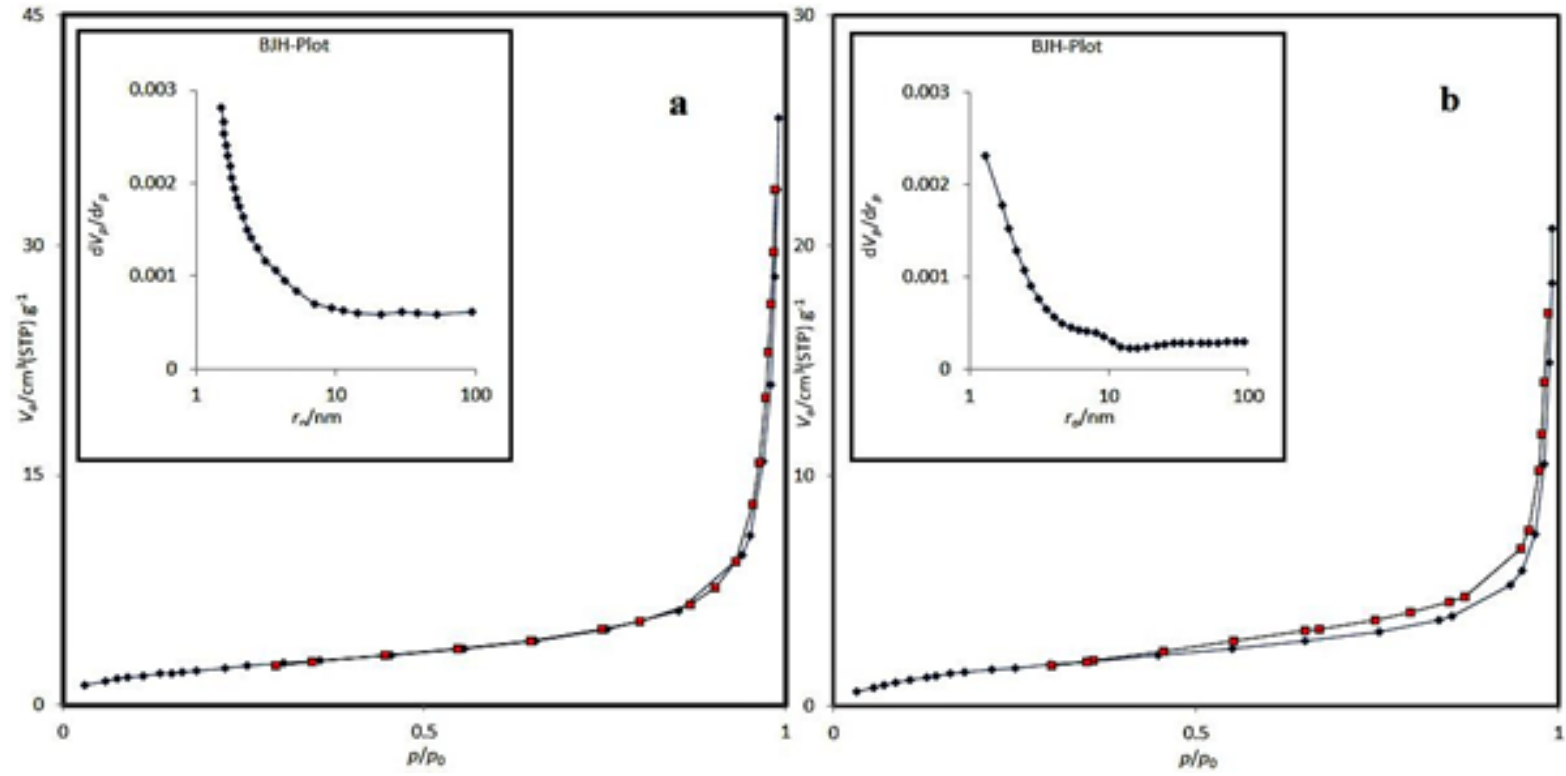

Figure 6

Nitrogen absorption-desorption and BJH plots of a) HY zeolite b) HY-N-SO3H 

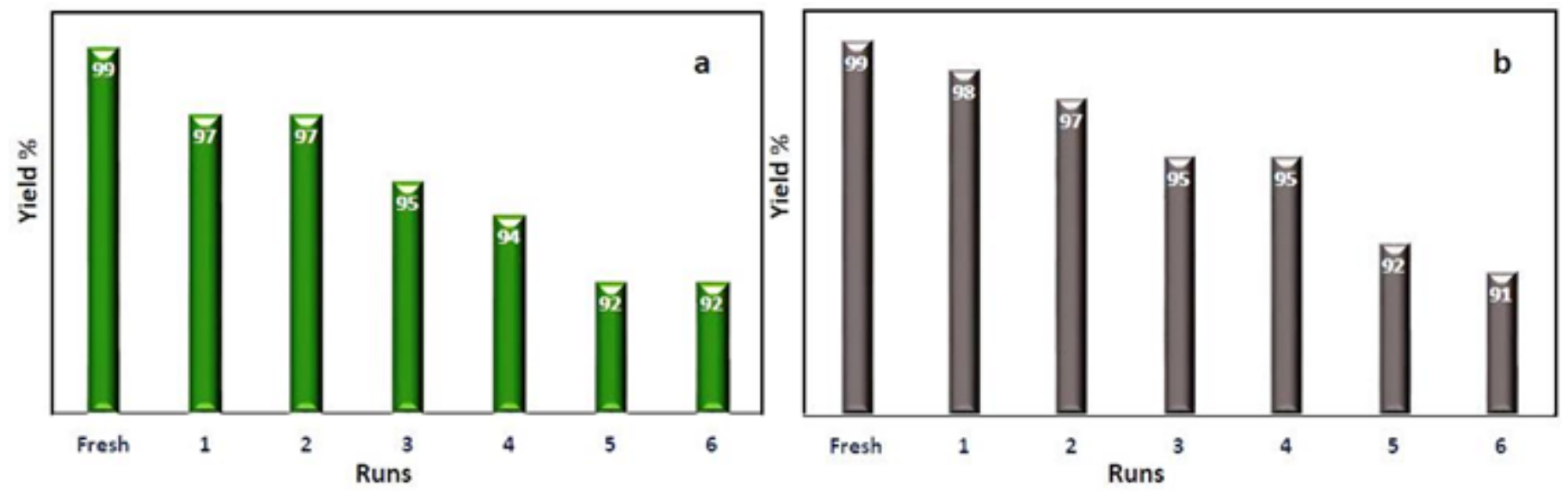

Figure 7

Catalytic efficiency of the recycled catalyst a) formylation of amines b) pechmann condensation
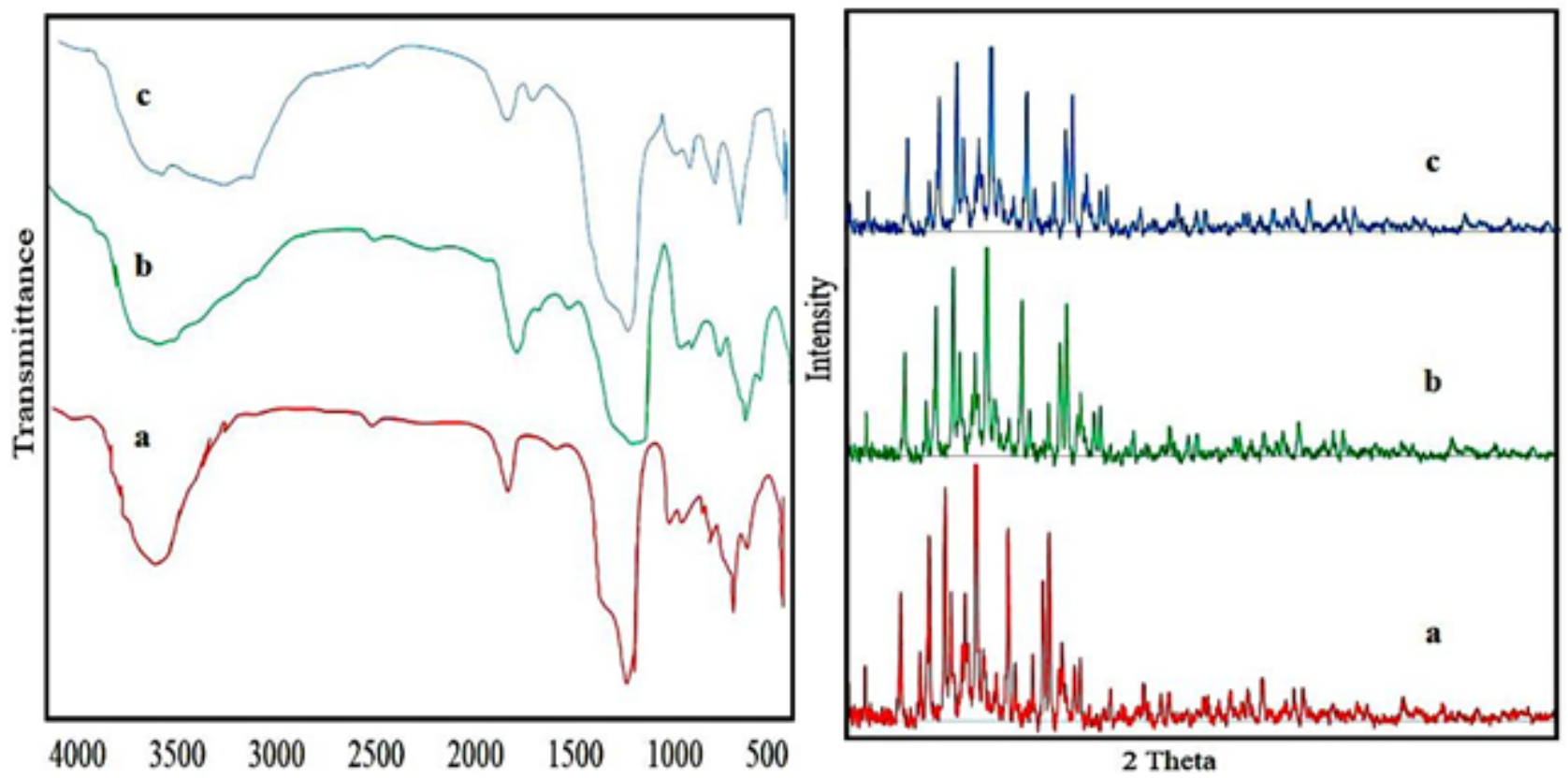

Figure 8

FT-IR spectra and XRD of fresh catalyst (a) and the recycled catalyst after last run for pechmann condensation (b) and for the formylation (c)

\section{Supplementary Files}

This is a list of supplementary files associated with this preprint. Click to download.

- Tables.docx

- Scheme01.png

- Scheme02.png

- Scheme03.png 